\title{
CONHECIMENTO ECOLÓGICO DA FLORA DA CAATINGA NA REGIÃO DO PROJETO DE INTEGRAÇÃO DO RIO SÃO FRANCISCO
}

\author{
Edjane Silva Damasceno ${ }^{1}$ \\ Daniela de Jesus Lima² \\ Renato Garcia Rodrigues ${ }^{3}$
}

Resumo: Este estudo de caso avalia os conhecimentos ecológicos da vegetação da Caatinga de viveiristas e estudantes através de uma oficina de produção de mudas na área de influência do Projeto de Integração do São Francisco. A análise quanti-qualitativa permitiu verificar que, apesar de características diversificadas entre os sujeitos, eles conhecem algumas adaptações das plantas nativas, porém, há uma confusão conceitual entre espécie endêmica e exótica, principalmente para parte dos estudantes que classificaram uma espécie exótica (Prosopis juliflora) como nativa. A oficina contribuiu ao saber ecológico e florístico dos sujeitos. Os resultados indicam temas relevantes para constar em práticas de ensino formal e não-formal.

Palavras-chave: Produtores de Mudas; Capacitação; Formação; Rede de Sementes do PISF; Educação Ambiental.

Abstract: This case study evaluates the ecological knowledge of the Caatinga vegetation of nurserymen and students through a sapling production workshop in the influence area of the São Francisco Integration Project (PISF).The quantiqualitative analysis showed that, although 1) the participants had diverse characteristics, they 2) knew some adaptations of native plants, however, 3) there is a conceptual confusion between endemic and exotic species, particularly to 4) part of the students who classified an exotic species (Prosopis juliflora) as native. The workshop contributed to the participants'; ecological and floristic knowledge. The results indicate relevant topics to be included in formal and non-formal education practices.

Keywords: Sapling Producers; Training; Formation; PISF Seed Network; Environmental Education.

\footnotetext{
1 Universidade Federal do Vale do São Francisco - UNIVASF. E-mail: damasceno.des@gmail.com. Link para o Lattes: http://lattes.cnpq.br/9658883485815468

2 Universidade Federal da Bahia - UFBA. E-mail: daniela_ufba@hotmail.com. Link para o Lattes: http://lattes.cnpq.br/4659076815234471

3 Universidade Federal do Vale do São Francisco - UNIVASF. E-mail: renato.garcia@univasf.edu.br. Link para o Lattes: http://lattes.cnpq.br/7948413419854650
} 


\section{Introdução}

O Projeto de Integração do Rio São Francisco com as Bacias Hidrográficas do Nordeste Setentrional, conhecido popularmente como Projeto São Francisco ou PISF é uma obra de infraestrutura hídrica do governo brasileiro. Segundo o Ministério do Desenvolvimento Regional brasileiro, seu objetivo principal é garantir a segurança hídrica de milhões de pessoas da região semiárida do Nordeste do Brasil através da captação da água do Rio São Francisco e sua condução para bacias hidrográficas dos estados de Pernambuco, Ceará, Paraíba e Rio Grande do Norte. A fim de atender as demandas de resgate de sementes previsto no Programa de Conservação da Fauna e Flora - Subprograma Flora e viabilizar a produção de mudas para execução do Programa de Recuperação de Áreas Degradadas do PISF, o Núcleo de Ecologia e Monitoramento Ambiental (NEMA) da Universidade Federal do Vale do São Francisco (UNIVASF), sediado em Petrolina-PE, formou em 2015, a Rede de Sementes do Projeto de Integração do São Francisco. A partir de então, a Rede tem se estruturado, aumentado o número de parceiros e contribuído com os esforços de compensação florestal relacionados ao licenciamento ambiental do PISF, bem como, no fornecimento de sementes nativas às comunidades influenciadas direta e indiretamente pela obra e no suporte e capacitação técnica a viveiristas parceiros para produção de mudas nativas do ecossistema Caatinga.

A produção de mudas nativas da Caatinga exige atenção especial sobre o funcionamento do ecossistema. Pereira (2011) aponta que o conhecimento e entendimento das particularidades de cada espécie são os primeiros passos a serem tomados por produtores de mudas antes de dar início a produção. Mudas mais resistentes às pressões ambientais, como por exemplo a seca, podem ter chances de sobrevivência maiores após o plantio (CRUZ; ANDRADE; FEITOSA, 2016; CUNHA et al., 2005). Atrelado a isso, o plantio de mudas com alta riqueza de espécies nativas provenientes de viveiros, é uma das alternativas mais utilizadas para recuperação de áreas degradadas (PALMA; LAURANCE, 2015; RODRIGUES et al., 2011) como algumas áreas encontradas no PISF. Por isso, a compreensão sobre a vegetação e o funcionamento da Caatinga pode garantir uma produção de mudas de qualidade e orientar a população local sobre o ecossistema.

A partir disso, entende-se que o endemismo se refere a ocorrência de espécies exclusivamente em uma determinada região ou ecossistema. De acordo com Dryflor (2016) florestas secas, como a Caatinga, apresentam elevados níveis de endemismo. A Caatinga possui uma proporção relativamente alta de espécies exclusivas (endêmicas) quando comparada com outras florestas secas do mundo (SILVA; LEAL; TABARELLI, 2017). Silva e Souza (2018) dividiram-na em nove sub-regiões biogeográficas com diferentes tipos de vegetação, as quais variam em função de um índice de aridez. A flora da Caatinga abrange um total de 4.657 espécies de plantas produtoras de sementes, das quais quase $20 \%$ são endêmicas (BFG, 2015) e estão 
localizadas em sua maioria nas Chapadas Diamantina e do Araripe, no nordeste do Brasil (SILVA; SOUZA, 2018; MANHÃES et al., 2016).

As plantas da Caatinga apresentam várias adaptações estratégicas de sobrevivência. Santiago e colaboradores (2016) apresentam dentre outras, três adaptações interessantes na abordagem sobre produção de mudas, são elas: 1) a queda das folhas durante a estação seca, como uma estratégia usada pelas plantas para evitar a perda de água, que acontece principalmente pelas folhas; 2) caules esverdeados fotossintetizantes, que muitas vezes são capazes de absorver carbono usando água de forma mais eficiente do que as folhas e o 3) desenvolvimento de raízes profundas, que auxiliam na absorção de água em camadas mais profundas do solo, o que pode explicar a permanência das folhas durante o período seco em algumas espécies. Outra adaptação das plantas desse ecossistema refere-se ao investimento em estruturas de reserva energética (SALA; WOODRUFF; MEINZER, 2012). Os xilopódios (tubérculos, "batata da raiz") presentes nas raízes da espécie nativa Spondias tuberosa (umbuzeiro) são exemplos de estruturas que armazenam significativa quantidade de água e açucares auxiliando na sobrevivência da espécie durante o período seco (DUQUE, 2004).

O conhecimento sobre espécies nativas e exóticas influencia na convivência da população local com o ecossistema. As espécies são consideradas nativas quando ocorrem no mesmo ecossistema de sua origem. As exóticas por sua vez, são aquelas que estão fora do seu ecossistema de origem. Miller (2005) mostra que a evidência e relevância biológica das espécies nativas tem sido prejudicada pela crescente urbanização e visão alterada dos meios naturais e com isso, ressalta a importância das interações humanas com o ambiente natural em sua volta. Soma-se a isso, a dificuldade no reconhecimento de espécies nativas e os possíveis problemas que espécies exóticas podem trazer ao contexto dos biomas (PROENÇA; DAL-FARRA; OSLAJ, 2017). Sob esse aspecto, Davis e colaboradores (2011) acrescentam que ao considerar espécies exóticas é preciso enfatizar os impactos ambientais que elas podem causar ao se tornarem invasoras e não apenas o fato delas não serem originárias do ecossistema onde situam-se. Logo, o discernimento da diversidade nativa em conjunto com um enfoque regional e global formam uma estratégia relevante de Educação Ambiental, conforme sinaliza Proença e colaboradores (2017) e Dias e Bonotto (2012).

Diante desse cenário, a atuação da Rede de Sementes do PISF na região de influência do Projeto de Integração do São Francisco emerge como um importante mecanismo social de formação crítica e propositiva capaz de mobilizar agentes sociais no semiárido para ações ambientais emancipatórias de preservação do ecossistema Caatinga. Por se tratar de uma proposta de ação implantada por uma universidade pública e considerando a importância do debate sobre ecologia da Caatinga na produção de mudas nativas nos meios educacionais e rurais, a relevância deste estudo de caso pode ser delineada sob três principais perspectivas. A primeira delas, no que se refere a difusão do conhecimento científico da universidade para a sociedade de forma 
a gerar troca de experiências com outras instituições que atuam ou pesquisam a temática. A segunda, refere-se a importância do uso de oficinas como ferramentas de Educação Ambiental para proporcionar troca de experiências e conhecer as demandas de agentes que produzem subsistência atrelada direta ou indiretamente a conservação do meio ambiente, bem como gerar um local de interações para conectá-los ao meio natural onde vivem diariamente. E a última, e não menos importante, da contribuição dos resultados obtidos para aprimoramento das capacitações das redes de sementes baseado nas demandas dos conhecimentos locais.

Nesse sentido, para que as capacitações contribuam para as demandas locais é preciso tecer um olhar sobre os sujeitos envolvidos. Quem são? Quais as suas compreensões sobre ecologia da Caatinga? Quais saberes apresentam sobre a flora nativa da Caatinga? A fim de responder essas questões, o objetivo deste trabalho consiste em investigar de que forma os aspectos da vegetação e ecologia da Caatinga são compreendidos por produtores de mudas e estudantes da região semiárida, através da realização de uma oficina de produção de mudas nativas em municípios influenciados pelo Projeto de Integração do São Francisco.

\section{Materiais e métodos}

\section{Oficina de produção de mudas nativas}

A pesquisa foi realizada no âmbito da oficina de produção de mudas nativas da Caatinga ofertada pela Rede Sementes do PISF, uma iniciativa do Núcleo de Ecologia e Monitoramento Ambiental da Universidade Federal do Vale do São Francisco de Petrolina-PE. Essa oficina integra uma das ações realizada pela Rede de Sementes que se refere a capacitação técnica para atividades de produção de mudas nativas na região de influência do PISF. O público atendido pelas atividades cotidianas da Rede inclui pesquisadores, estudantes, produtores de mudas de viveiros familiares, comunitários, municipais, privados, de Organizações Não Governamentais, de instituições de ensino, dentre outros de diferentes faixas etárias e graus de instrução.

A capacitação técnica ocorre através de oficinas ministradas à parceiros da Rede de Sementes em municípios de influência direta e indireta do PISF e tem por objetivo proporcionar diferentes impactos positivos para os participantes, tais como: 1) formação de mão de obra qualificada para atuar em viveiros de produção de mudas e atividades relacionadas, 2) oportunidade para empreendedorismo e geração de renda atrelado à conservação e restauração da biodiversidade, 3) aumento da qualidade das mudas nativas produzidas na região do PISF e 4) sensibilização e Educação Ambiental sobre ecologia e características da vegetação da Caatinga relevantes para produção de mudas.

Foi esse último objetivo que se constituiu o objeto de investigação neste artigo. A oficina foi organizada em uma formação teórico-prática com duração média de cinco horas. Do ponto de vista metodológico, a oficina foi conduzida 
por meio de uma exposição dialogada utilizando o recurso de slides com fotos e questões problematizadoras a fim de gerar discussões e produção do conhecimento sobre temas importantes ao entendimento da produção de mudas nativas, como por exemplo, ecologia e adaptações das plantas da Caatinga. A parte prática incluiu atividades de manuseio de frutos e sementes, superação de dormência de sementes ("quebra de dormência"), preparação de substrato para mudas, semeio e organização do viveiro de mudas.

\section{Caracterização do grupo de estudo}

O sujeito estudado nesta investigação inclui dois grupos: grupo 1) viveiristas e pessoas interessadas em produção de mudas, e grupo 2) estudantes do ensino médio técnico subsequente. O grupo 1, foi formado por pessoas que trabalhavam no Viveiro Municipal de Bodocó-PE, de um Instituto Federal do Sertão Pernambucano e interessados em produção de mudas residentes em Jatobá-PE, onde há um viveiro de mudas comunitário localizado na comunidade indígena Bem-querer de Cima. Enquanto o grupo 2, formou-se por estudantes do ensino médio técnico subsequente, em sua maioria, do curso de agropecuária de um Instituto Federal do Sertão Pernambucano.

\section{Metodologia, coleta, amostragem e análise de dados}

Do ponto de vista metodológico, esta pesquisa foi desenvolvida por meio de um estudo de caso seguindo uma abordagem mista, apesar de termos priorizado a técnica quantitativa. Para Yin (2001), esse tipo de estudo busca compreender decisões visando esclarecer motivos e formas de implementação para conhecer os resultados de uma determinada realidade nas condições do fenômeno pesquisado. A abordagem mista proposta por Creswell (2014), integra técnicas quantitativa e qualitativa de maneira complementar, o que segundo Souza e Kerbauy (2017) proporciona mais e melhores informações dos dados investigados.

As coletas de dados ocorreram por meio de questionários aplicados antes e após as oficinas. O questionário semiestruturado foi constituído por 17 perguntas, das quais as oito primeiras definiram o perfil do respondente, as cinco seguintes mapearam o conhecimento ecológico da vegetação nativa da Caatinga, e as quatro últimas verificaram a eficácia e relevância dos temas abordados durante a oficina. As 14 primeiras perguntas foram respondidas antes do início da parte teórica da oficina e as quatro últimas, ao término.

No total, foram colhidas informações de 29 pessoas, das quais 11 pertencem ao grupo 1 e 18 ao grupo 2, 100\% dos participantes em ambos os grupos nas oficinas. Os respondentes do questionário não foram identificados a fim de evitar julgamentos e respeitar orientações éticas. A análise foi baseada em estatística descritiva, interpretações e comparações com a literatura especializada. 
As respostas da última e única questão aberta do questionário foram agrupadas em dois arquivos de texto, a fim de elaborar duas nuvens de palavras, uma para cada grupo. Aqui, o uso das nuvens de palavras não tem a finalidade de analisar o discurso dos grupos, mas sim expor graficamente a frequência dos dados linguísticos mencionados por cada grupo. A frequência das palavras é expressa pelo tamanho e cor delas, ou seja, palavras de mesmo tamanho e cor apresentam a mesma frequência de repetição.

A elaboração de tabelas e gráficos foi realizada no software Microsoft Office Excel. A construção das nuvens de palavras foi realizada no software $\mathrm{R}$ (RCore Team, 2019) através do pacote "wordcloud" (FELLOWS, 2018) utilizando a função de mesmo nome "wordcloud" para plotar a nuvem de palavras de cada grupo. Através do pacote "tm" (FEINERER; HORNIK, 2019) foi possível limpar os textos para melhorar a leitura e visualização das nuvens de palavras, utilizando a função "tm_map" que realiza transformações nos textos, tais como tornar todas as letras dos textos em letras minúsculas ("content_transformer"), remover números ("removeNumber"), remover palavras de parada como "de" e "para" ("stopwords"), remover espaços em branco extras nos textos ("stripwhitespace") e remover palavras específicas, as quais jugamos não importantes, como "bom", "excelente", "ótimo", "aprendi", "não", "e", "existir", "existe", "sobre", "sobra", "nome", "tanto", "somente", "questões", "questão", "quanto", "ocorre", "meio", "sobre", "algumas" etc.

\section{Resultados e discussão}

\section{Perfil dos respondentes}

Os sujeitos respondentes desta pesquisa incluíram viveiristas e pessoas interessadas em produção de mudas (grupo 1) e estudantes das ciências agrárias (grupo 2). A faixa etária, escolaridade e renda mensal foram características que mais distinguiram os grupos. Enquanto os respondentes do grupo 1 eram em sua maioria adultos de 35 a 44 anos $(36,4 \%)$ com ensino superior completo ou incompleto $(27,3 \%)$ e renda mensal de um a dois salários-mínimos $(36,4 \%)$, os do grupo 2 eram jovens de no máximo 24 anos $(88,9 \%)$ com ensino médio completo $(55,6 \%)$ e sem renda mensal $(77,8 \%)$.

Considerando todos os sujeitos incluídos no estudo $(N=29)$, uma elevada amplitude quanto a faixa etária dos sujeitos foi encontrada, desde respondentes com idade até 24 anos $(58,7 \%)$ a sujeitos com mais de 55 anos $(3,4 \%)$, uma proporção equilibrada entre homens $(55,2 \%)$ e mulheres $(44,8 \%)$, a maior parte deles possuíam ensino médio completo (34,5\%), renda mensal variando entre zero $(58,7 \%)$ e mais de cinco salários mínimos $(3,4 \%)$, incluindo um respondente que trabalhava a mais de 6 anos $(3,4 \%)$ com produção de mudas, apesar da grande maioria $(79,5 \%)$ nunca ter trabalhado na área (Tabela 1). 
Tabela 1: Perfil socioeconômico dos sujeitos. Porcentagem total inclui todos os respondentes do estudo ( $N=29)$, grupo 1: viveiristas e interessado em produção de mudas $(n=11)$ e grupo 2: estudantes das ciências agrárias $(n=18)$.

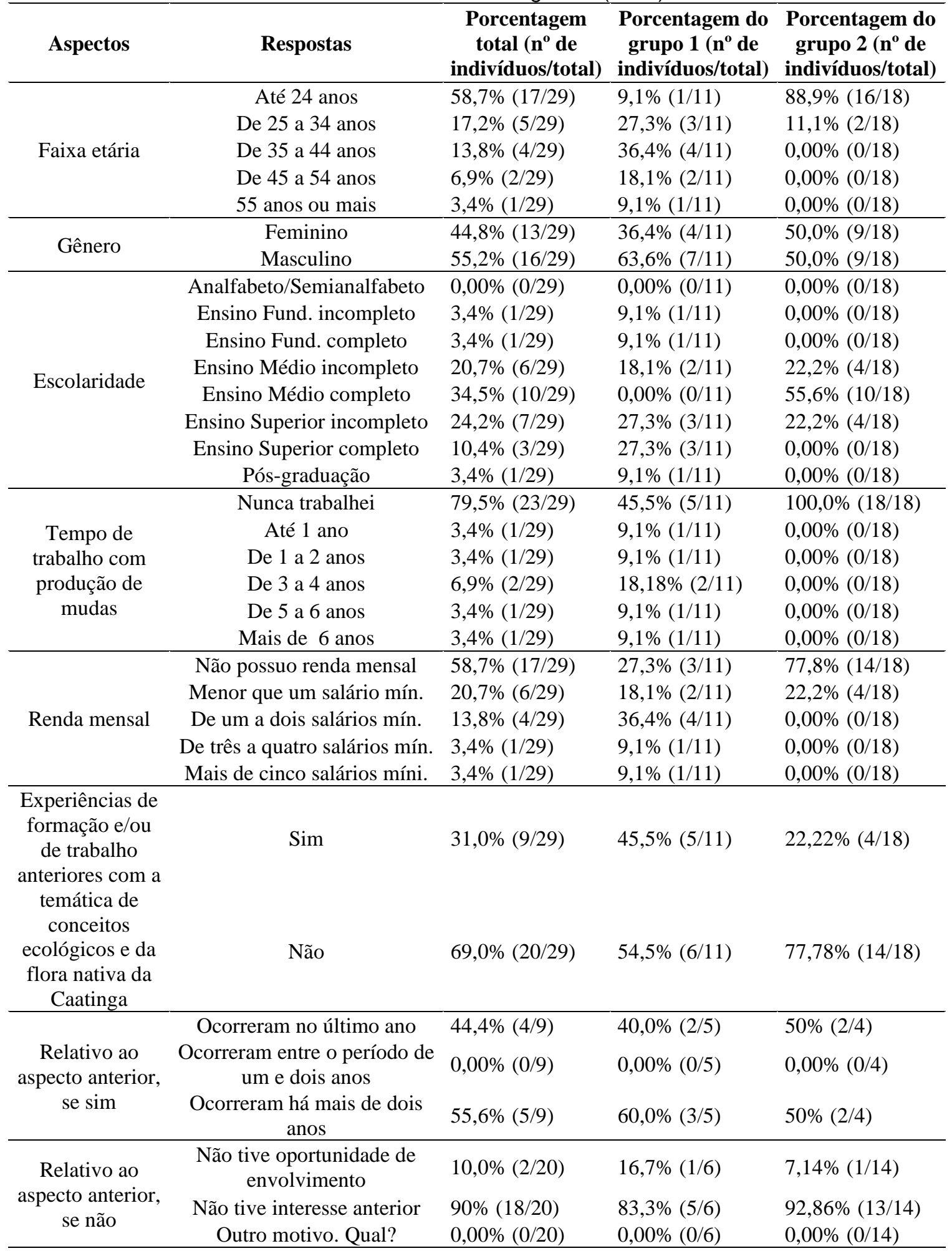

Fonte: Autoria própria (2020)

Revbea, São Paulo, V. 16, № 3: 237-255, 2021. 
Essa amplitude nas características dos sujeitos reflete a diversidade da atuação da Rede de Sementes do PISF. Fato que exigiu maior empenho em estabelecer uma pedagogia capaz de lidar com as diferenças entre os sujeitos, na sensibilização e capacitação dos participantes da oficina de produção de mudas nativas da Caatinga. Isso porque a compreensão sobre fatores ambientais difere entre indivíduos e grupos de acordo com vários aspectos como o nível de instrução e experiências que possuem (BRANDALISE, 2009). Adultos tendem a ser mais heterogêneos em termos de motivação e interesse e a possuírem um volume maior de experiências quando comparados com crianças e jovens. Knowles e colaboradores (2009) evidenciam isso através da necessidade de individualização e uso das experiências dos aprendizes em uma situação de ensino, como a proposta da oficina.

Grande parte dos respondentes nunca participou de formações ou trabalhos anteriores relacionados à temática proposta (69\%), por não terem interesse no tema até então ( $90 \%$; Tabela 1$)$. Isso sugere que, independentemente da diversidade do sujeito analisado, os envolvidos demonstraram interesse em conhecer sobre os subtemas que envolvem a produção de mudas nativas da Caatinga na ocasião da oficina. Tal motivação, provavelmente, foi influenciada por um nível razoável de conscientização ambiental da população local; pelo fato de grande parte dos respondentes $(n=18)$ serem estudantes das ciências agrárias e pela crescente demanda por sementes e mudas na região decorrente do avanço de empreendimentos como o PISF, parques eólicos e solares. Esses empreendimentos são obrigados legalmente a adotarem medidas de recuperação e ou compensação ambiental das áreas degradadas por suas atividades. Como consequência tem sido exigido o plantio de mudas com alta riqueza de espécies nativas provenientes de viveiros, umas das técnicas mais utilizadas para recuperação destas áreas (PALMA; LAURANCE, 2015; RODRIGUES et al., 2011).

\section{Ausência de clareza no conhecimento prévio sobre espécie endêmica e exótica}

Um terço dos sujeitos não souberam conceituar espécie endêmica antes da oficina, independente de qual grupo pertenciam. Os demais sabiam ou confundiram 0 conceito de espécie endêmica com outros conceitos apresentados nas opções da questão. Os resultados sugerem que não há um conceito claro sobre endemismo para os sujeitos analisados (Figura 1). Como o endemismo é importante para conservação de ecossistemas, esperava-se que ambos os grupos seriam capazes de conceituar endemismo corretamente. Ao contrário disso, o grupo 2, apesar de ser formado por estudantes das ciências agrárias, não soube reconhecer o conceito. Dentre as alternativas da questão foi exposto a definição de espécie exótica, que representou a maior parte das respostas $(44,4 \%)$, evidenciando uma confusão entre o conceito de espécie endêmica e exótica presente no grupo 2 (Figura 1a). A definição correta sobre espécie endêmica foi representada pela metade do grupo $1(54,5 \%)$, conforme esperado (Figura 1c).

Revbea, São Paulo, V. 16, № 3: 237-255, 2021. 
a) Uma espécie que não pertence ao ambiente onde vive, mas consegue se desenvolver nele

b) Não sei

c) Uma espécie exclusiva, ou seja, que só ocorre em um determinado local ou região geográfica

d) Uma espécie que não pertence ao ambiente onde vive e cresce rapidamente excluindo outras

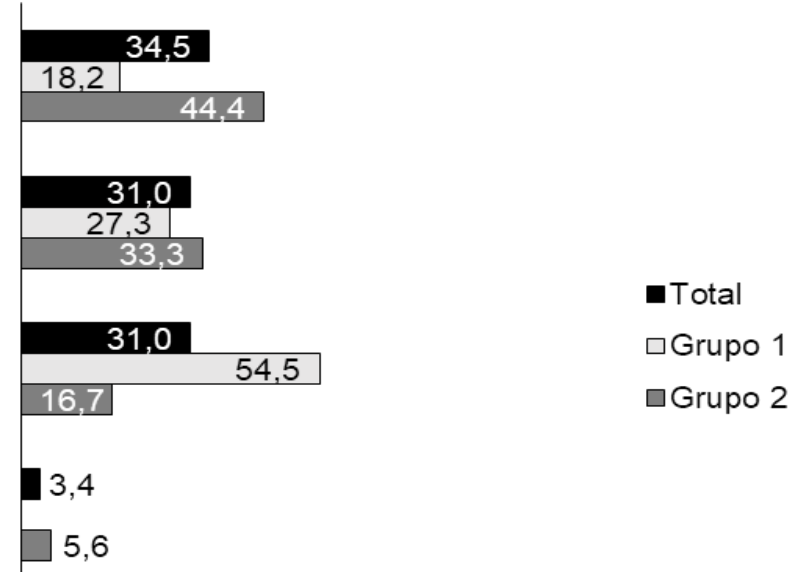

Figura 1. Porcentagem das respostas dadas pelos respondentes antes da oficina a pergunta "O que é uma espécie endêmica?'. No eixo y encontram-se as alternativas disponíveis no questionário: a) conceito de espécie exótica, c) conceito de espécie endêmica e d) conceito de espécie exótica invasora. Porcentagem total inclui todos os respondentes do estudo $(N=29)$, grupo 1: viveiristas e interessado em produção de mudas $(n=11)$ e grupo 2: estudantes das ciências agrárias $(n=18)$. Fonte: Autoria própria (2020).

A capacidade de conceituar endemismo refletiu na escolha de qual das espécies apresentadas é endêmica da Caatinga. Considerando as informações do Flora do Brasil 2020 (em construção), apenas o juazeiro (Ziziphus joazeiro) é endêmico da Caatinga. A metade do grupo $1(45,5 \%)$ escolheu corretamente 0 juazeiro (Figura $2 \mathrm{~b}$ ), refletindo um percentual semelhante $(54,5 \%)$ ao encontrado sobre o conceito de endemismo (Figura 1c). Este resultado sugere que parte do grupo 1 tem a capacidade tanto de reconhecer como de exemplificar o conceito de endemismo de maneira correta. Um raciocínio antagônico explica o resultado encontrado para o grupo 2, pois um terço das respondentes classificou o ipê-amarelo como endêmico da Caatinga (Figura 2c). Este erro é reflexo da falta de precisão em conceituar endemismo por este mesmo grupo (Figura 1a). O umbuzeiro (Spondias tuberosa) foi erroneamente escolhido como espécie endêmica da Caatinga por mais da metade dos sujeitos de ambos os grupos. Isto ocorreu provavelmente devido aos diferentes usos dados à espécie pela população do semiárido (PAODJUENAS et al., 2019). A espécie faz parte da identidade cultural nordestina desde muito cedo e pode ser vista em desenhos feitos por crianças para representar a flora da Caatinga (BITENCOURTT; MARQUES; MOURA, 2014). A identidade cultural é tão forte que integrantes da Cooperativa Agropecuária Familiar de Canudos, Uauá e Curaçá (norte da Bahia) consideram o umbuzeiro como uma espécie sagrada do sertão (BRASILEIRO, 2009). 


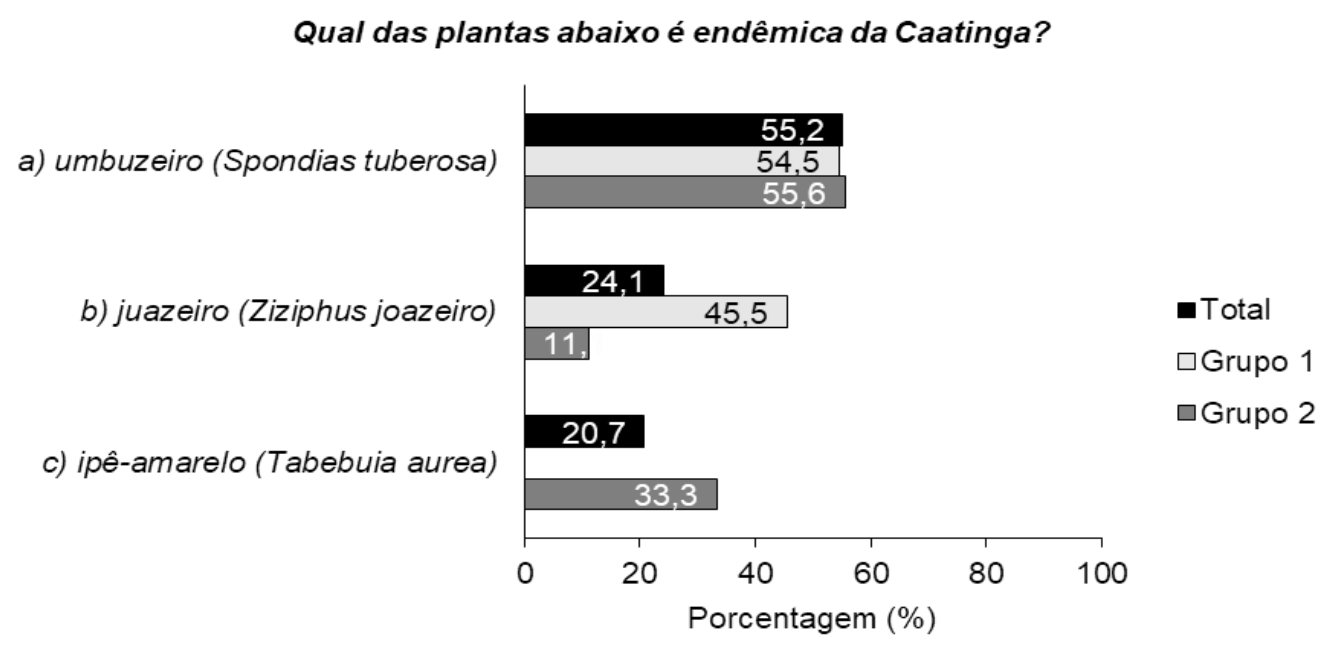

Figura 2: Porcentagem das respostas dadas pelos respondentes antes da oficina a pergunta "Qual das plantas abaixo é endêmica da Caatinga?". No eixo y encontram-se as alternativas disponíveis no questionário. Porcentagem total inclui todos os respondentes do estudo $(\mathrm{N}=$ 29), grupo 1: viveiristas e interessado em produção de mudas $(n=11)$ e grupo 2: estudantes das ciências agrárias $(n=18)$. Fonte: Autoria própria (2020).

Os sujeitos reconheceram a aroeira (Astronium urundeuva) como espécie nativa, porém mesmo que em menor proporção, a algaroba (Prosopis juliflora), uma espécie exótica, foi apontada como nativa. Para avaliar o conhecimento sobre espécie nativa, foram dadas aos respondentes três opções de espécies, das quais apenas a aroeira era nativa da Caatinga. Em geral, a maioria $(75,9 \%)$ classificou tal espécie como nativa da Caatinga (Figura 3 ). No entanto, chamou atenção a quantidade de estudantes (grupo 2) que considerou a algaroba uma espécie nativa $(n=6 ; 33,3 \%)$. O que demanda maior atenção e discussão dessa temática no ensino das ciências nas escolas. A algaroba é uma espécie originária da América Central e é considerada uma exótica invasora capaz de prejudicar ecossistemas onde se propaga (ANDRADE; FABRICANTE; OLIVEIRA, 2009, 2010). Apesar disso, é uma espécie presente na cultura do povo do semiárido brasileiro há décadas. Depois que foi introduzida no país como opção de forragem para animais (ALMEIDA et al. 2015), a espécie tem sido utilizada para outros fins pelas comunidades rurais como, fabricação de combustível, construção de cercas, uso medicinal e alimentício (ALBUQUERQUE et al., 2009; NASCIMENTO et al., 2009; ALBUQUERQUE et al., 2007;). Este significado cultural dado às espécies exóticas pode ser elevado quando comparado com espécies nativas, como registrado em uma comunidade tradicional do Estado de Pernambuco (SILVA; ANDRADE, 2004). 


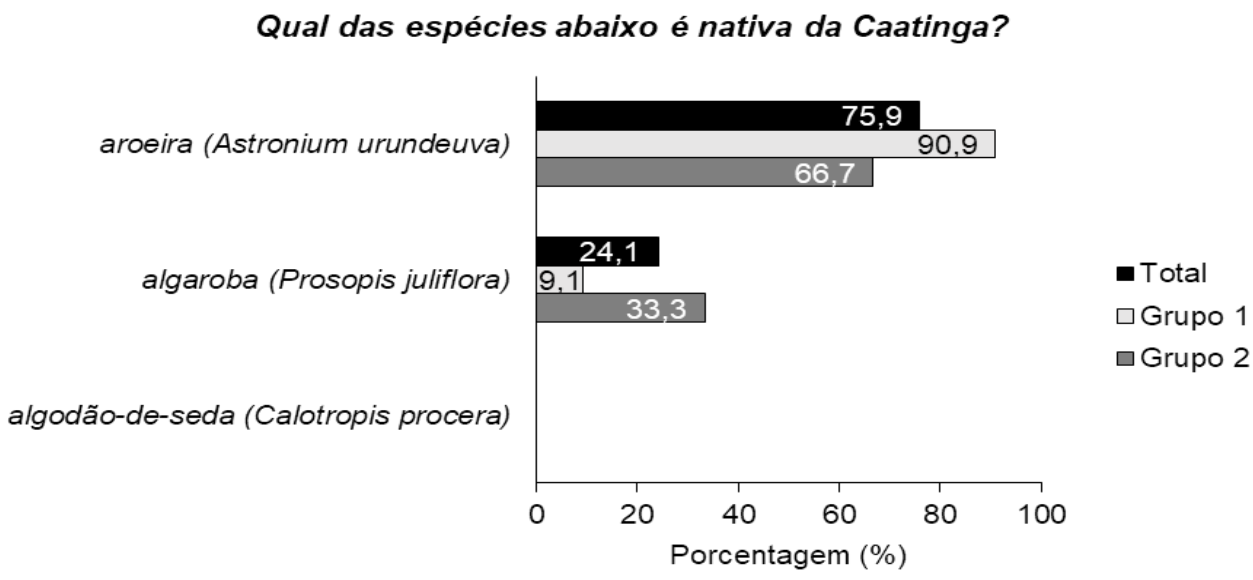

Figura 3: Porcentagem das respostas dadas pelos respondentes antes da oficina a pergunta "Qual das espécies abaixo é nativa da Caatinga?". No eixo y encontram-se as alternativas disponíveis no questionário. Porcentagem total inclui todos os respondentes do estudo $(\mathrm{N}=$ 29), grupo 1: viveiristas e interessado em produção de mudas $(n=11)$ e grupo 2: estudantes das ciências agrárias $(n=18)$. Fonte: Autoria própria (2020).

\section{Reconhecimento de adaptações das plantas nativas}

Os envolvidos na pesquisa conheciam as adaptações das plantas da Caatinga, independente de qual grupo pertenciam. Quando perguntados o porquê de as plantas ficarem sem folhas durante o período seco na Caatinga, a maioria $(82,8 \%)$ sabia que se tratava de uma adaptação das plantas desse ecossistema para evitar perda de água por transpiração (Figura 4). A vivência cotidiana com o ecossistema os faz experimentar os efeitos da seca e por consequência compreender as mudanças que ocorrem nos elementos naturais ao seu redor (TUAN, 2012). Caso o sujeito não possuísse tal vivência, os resultados poderiam ser diferentes, pois o fenômeno da queda de folhas ainda é algo curioso para muitas pessoas que não conhecem o ecossistema.

O xilopódio do umbuzeiro (Spondias tuberosa) também foi reconhecido como uma adaptação. Quase todos $(93,1 \%)$ conheciam que, da perspectiva do umbuzeiro, o xilopódio (tubérculos ou "batata" da raiz) tem a função de armazenar água e açúcares, que o auxilia a atravessar o período seco na Caatinga (Figura 5). O consumo de plantas nativas é parte integrante da cultura e identidade do povo em várias regiões do mundo (VOGGESSER et al., 2013). Paodjuenas e colaboradores (2019) mostram que a população do semiárido brasileiro usa os xilopódios do umbuzeiro de diferentes formas, como na fabricação de bolo, cocada, rapadura, doces e até mesmo in natura. Certamente, o uso alimentício do xilopódio influenciou a compreensão dos sujeitos sobre tal estrutura ser uma adaptação do umbuzeiro, pois quando consumido fica evidente que seu conteúdo é formado por água e açúcares. 
$\mathrm{Na}$ Caatinga, as plantas ficam sem folhas durante o período seco, porque:
São adaptadas a liberarem as folhas para evitar perder água por transpiração
A incidência solar seca as folhas, que acabam caindo espontaneamente

Neste período as folhas ficam velhas e precisam ser trocadas por folhas novas

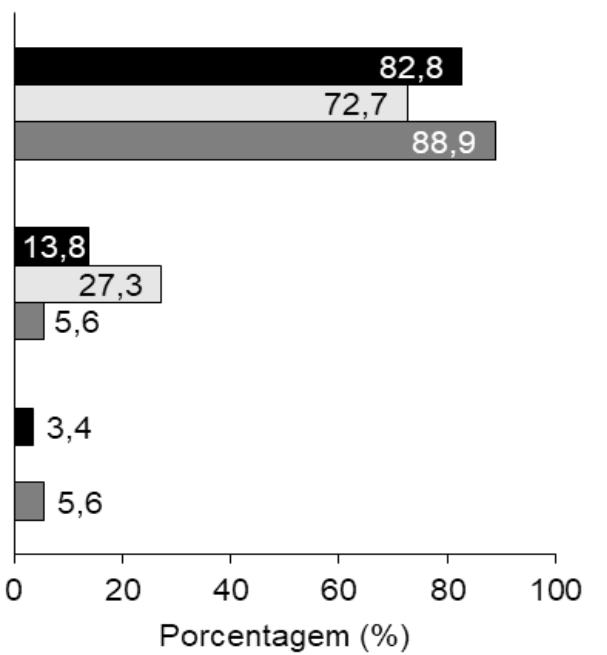

Figura 4: Porcentagem das respostas dadas pelos respondentes antes da oficina a pergunta

"Na Caatinga, as plantas ficam sem folhas durante o período seco, porque.". No eixo y encontram-se as alternativas disponíveis no questionário. Porcentagem total inclui todos os respondentes do estudo $(N=29)$, grupo 1: viveiristas e interessado em produção de mudas ( $n$

$=11$ ) e grupo 2: estudantes das ciências agrárias $(n=18)$. Fonte: Autoria própria (2020).

\section{Da perspectiva do umbuzeiro, o xilopódio (tubérculos, “batata”da raiz) tem a função de:}

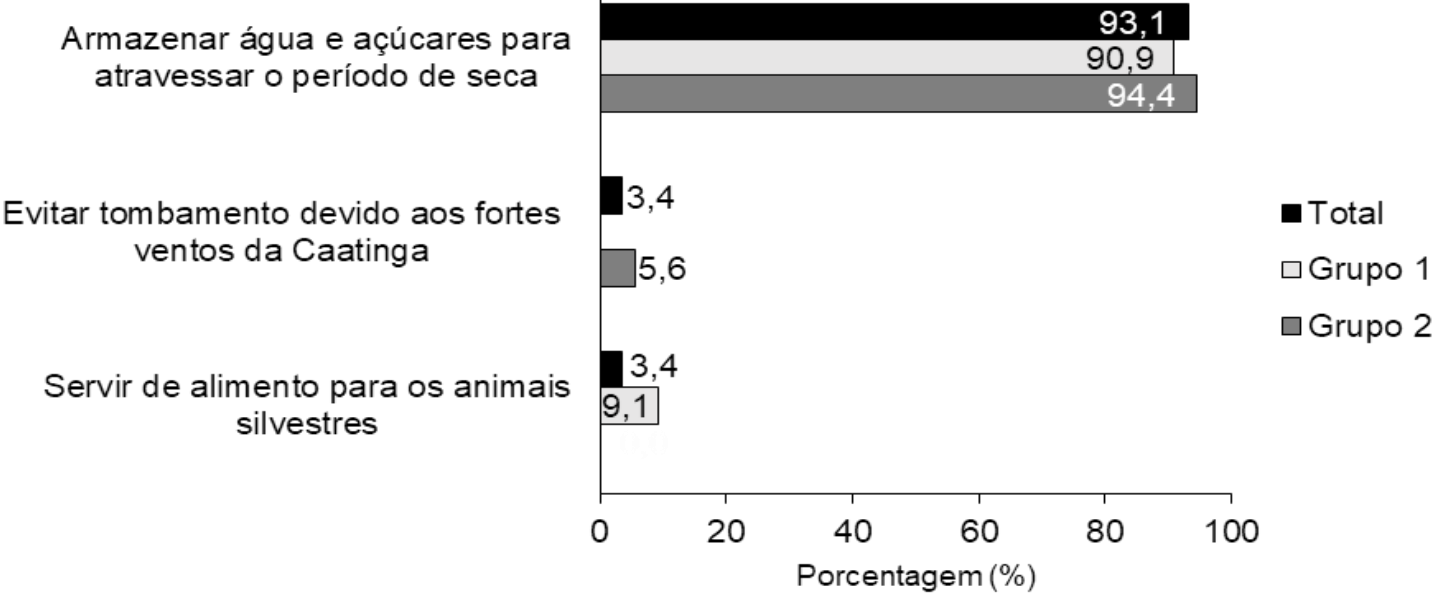

Figura 5: Porcentagem das respostas dadas pelos respondentes antes da oficina a pergunta "Da perspectiva do umbuzeiro, o xilopódio (tubérculos, "batata" da raiz) tem a função de:". No eixo y encontram-se as alternativas disponíveis no questionário. Porcentagem total inclui todos os respondentes do estudo $(\mathrm{N}=29)$, grupo 1: viveiristas e interessado em produção de mudas $(n=11)$ e grupo 2: estudantes das ciências agrárias $(n=18)$. Fonte: Autoria própria (2020). 


\section{Contribuição para o contexto local}

$\mathrm{O}$ endemismo na Caatinga foi apontado como novidade pelos sujeitos. As nuvens de palavras indicam que a confusão conceitual sobre endemismo impulsionou uma melhor compreensão após a oficina. Quando perguntados sobre as três principais novidades que a oficina os proporcionou, a palavra "endemismo" e "endêmica" foram as mais repetidas nas afirmações dos sujeitos, seguidas das palavras "juazeiro" e "Caatinga" (Figura 6). Espera-se que as informações transmitidas e as discussões geradas durante a oficina aumentem o sentimento de pertencimento e apreço pelo lugar onde os sujeitos vivem, contribuindo assim para conservação e recuperação da Caatinga. Com isso o papel social da universidade e das redes de sementes é cumprido, no que se refere a difusão de conhecimentos sobre a vegetação nativa para 0 contexto local.

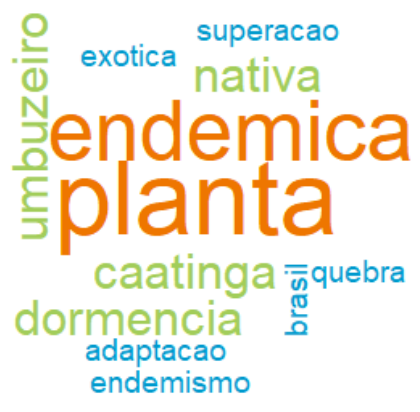

Grupo 1

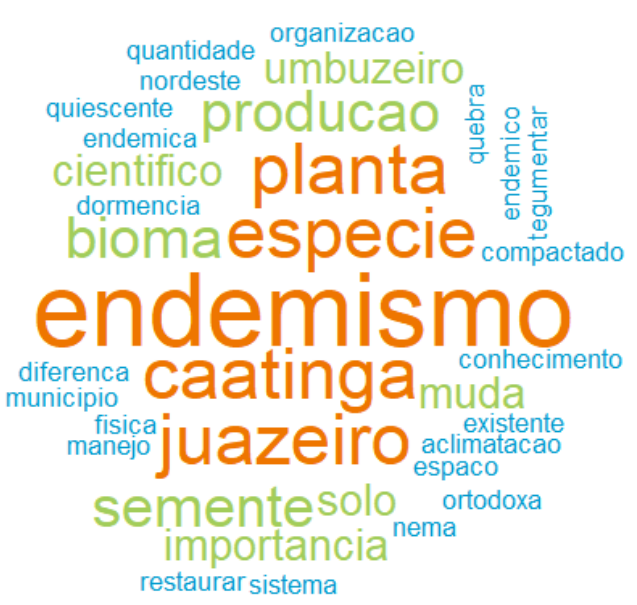

Grupo 2

Figura 6: Nuvens de palavras geradas a partir da escrita das respostas da pergunta "Escreva três palavras ou breves expressões, que expressem o que de novo sobre ecologia e plantas da Caatinga você conheceu, que antes da oficina você não tinha conhecimento." realizada após a oficina. Palavras em cor laranja apresentam frequência entre 6 a 4 citações, cor verde entre 3 a 2 citações e cor azul 1 citação. Grupo 1: viveiristas e interessado em produção de mudas ( $\mathrm{n}=$

11) e grupo 2: estudantes das ciências agrárias $(n=18)$. Fonte: Autoria própria (2020).

Todos os conceitos abordados na oficina contribuíram positivamente à compreensão prévia dos sujeitos. De maneira geral, ambos os grupos avaliaram com notas altas o quanto cada tema acrescentou em seus conhecimentos através de uma escala de zero a dez (Figura 7). Dentre os temas avaliados, a produção de mudas e o conhecimento sobre espécies nativas e exóticas se destacaram por receberem notas altas com maior frequência (Figura $7 \mathrm{c}, \mathrm{d}, \mathrm{g}, \mathrm{h}$ ), indicando que são os principais temas que contribuíram para a grande maioria dos sujeitos. Todos os temas foram 
avaliados acima de cinco, com exceção da compreensão sobre endemismo para uma pequena parte dos indivíduos (Figura 7 e, f). Isso indica que uma parcela baixa dos sujeitos já compreendia tal conceito, o que corrobora os resultados encontrados antes da oficina. Estes resultados indicam que uma parte considerável das informações transmitidas foram novas para o público.

Esses resultados conferem uma relevância significativa para a região de atuação. Visto que, adultos, jovens e crianças possuem uma visão da Caatinga inclinada para considerá-la uma região com pouca vida, com vegetação limitada a cactos e árvores secas e irrelevante para manutenção da biodiversidade nacional (BARBOSA et al., 2012; BARBOSA; BARBOSA, 2011). As espécies endêmicas são comuns em florestas secas como a Caatinga e requerem atenção singular para conservação e manutenção do ecossistema (SILVA; LEAL; TABARELLI, 2017). Logo, aumentar o conhecimento sobre endemismo, espécies nativas e exóticas é relevante para ressignificar o ecossistema Caatinga para os participantes.
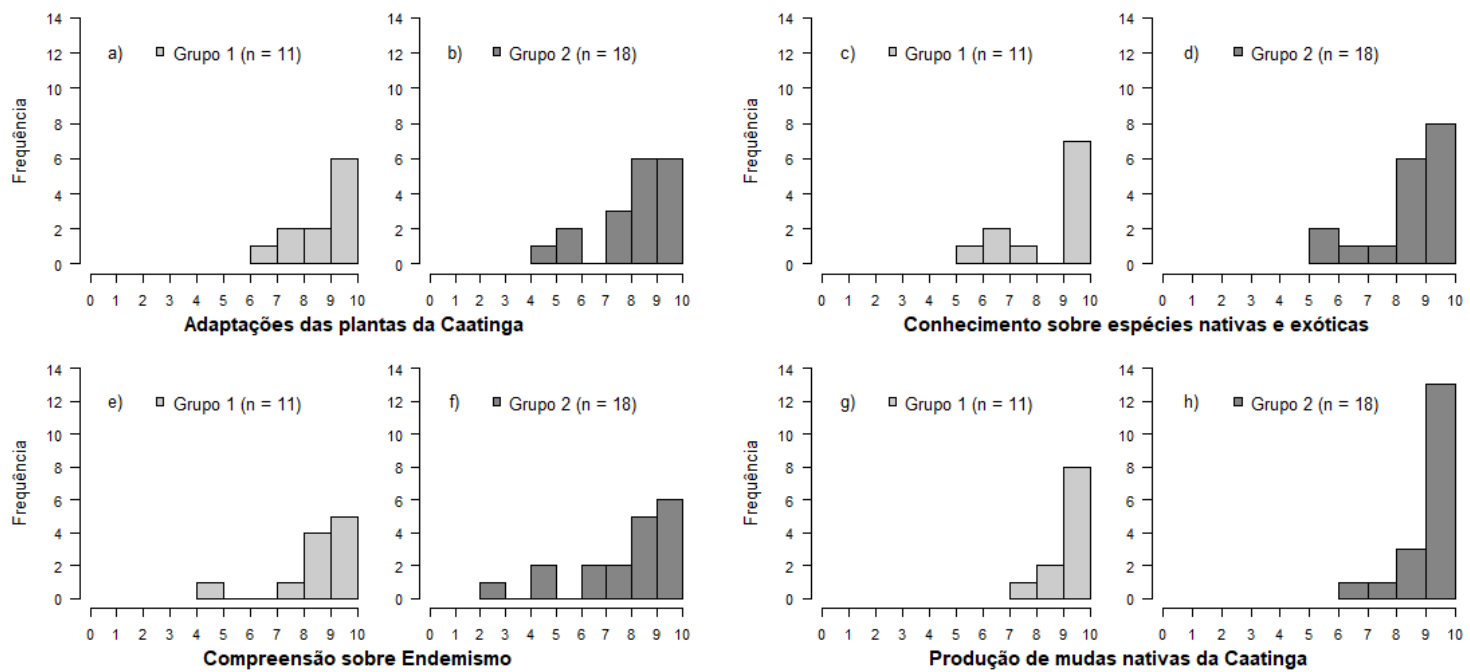

Figura 7: Histogramas de frequência das notas dadas para a pergunta "Em que medida, (considerando uma escala crescente) a oficina acrescentou em seus conhecimentos para cada um dos seguintes conceitos e conteúdos abaixo?' realizada pós a oficina. Grupo 1: viveiristas e interessado em produção de mudas $(n=11)$ e grupo 2: estudantes das ciências agrárias $(n=18)$. Fonte: Autoria própria (2020).

A oficina também contribuiu para capacitação em produção de mudas nativas da Caatinga. Independente do grupo, para a maioria dos sujeitos a formação promovida pela Rede de Sementes do PISF se adequa de maneira satisfatória ao trabalho cotidiano no viveiro ou em outro local de trabalho que atuavam (Figura 8a). Da mesma forma que, para quase todos $(\mathrm{N}=28)$ as informações apresentadas foram consideradas úteis para produção de mudas que executam ou executarão algum dia (Figura 8b). 

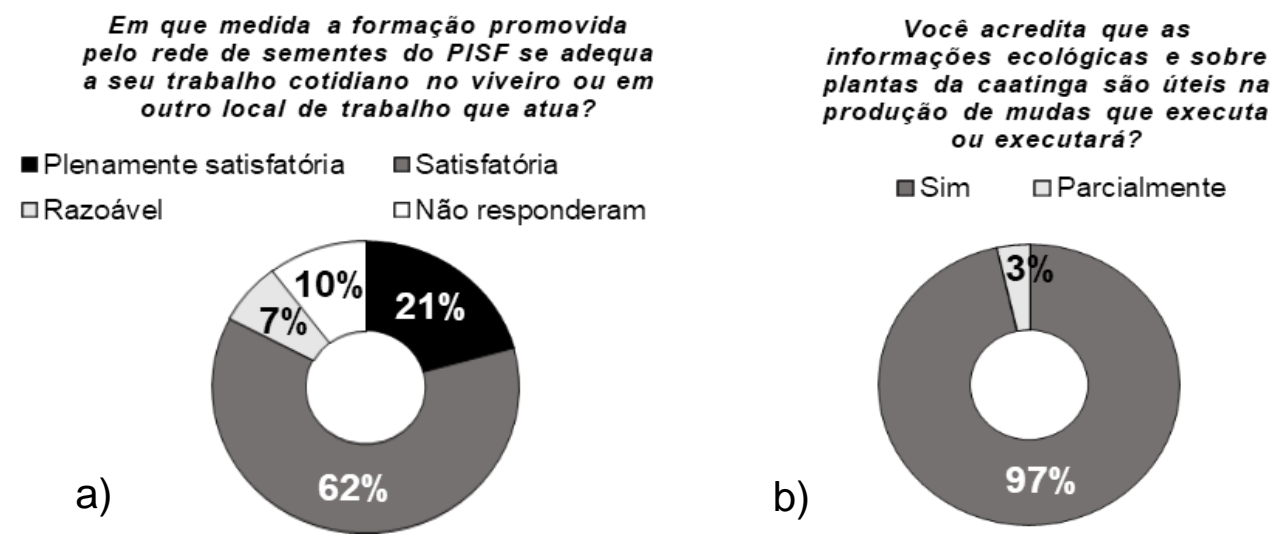

Figura 8: Porcentagem das respostas dadas pelos sujeitos após a oficina $(\mathrm{N}=29)$.

Fonte: Autoria própria (2020).

Os resultados alcançados neste trabalho evidenciam dois dos serviços prestados por redes de sementes: 1) o fornecimento de material vegetal para restauração, gerando benefícios socioeconômicos como consequência (URZEDO et al., 2020). Aumentar a qualidade e quantidade do fornecimento de material vegetal implica em investir na capacitação de sujeitos para produção de mudas. Uma vez capacitados, os viveiristas tornam-se agentes multiplicadores de Educação Ambiental nas comunidades onde residem e em seu empreendimento, como por exemplo aderindo ao escopo de viveiro educador, cuja produção de mudas torna-se a porta de entrada para um processo de construção do conhecimento envolvendo pessoas em discussões sobre a vivência e enfrentamento de problemas socioambientais (LEMOS; MARANHÃO, 2008). E 2) transmitir informações científicas sobre flora e ecologia para somar aos saberes locais e experiências individuais dos sujeitos. Uma vertente importante da atuação com as comunidades, de modo a se estabelecer uma via de mão dupla, pela qual os conhecimentos científicos chegam até meios populares e os conhecimentos populares agregam para construção do científico.

\section{Considerações finais}

Apesar da diversidade de características socioeconômicas, observa-se que os sujeitos deste caso conhecem algumas das adaptações que as plantas da Caatinga possuem para evitar perda d'água. Porém, a compreensão dos conceitos de espécie endêmica e exótica não é tão clara, principalmente, para os estudantes. Desta forma, torna-se urgente e fundamental a necessidade de levar para o ambiente formal de ensino temas ecológicos de relevância local, como estes conceitos de endemismo e espécie exótica. Além do conceito é importante destacar também exemplos e informações que proporcionem mudanças na percepção do ambiente desses estudantes e auxiliem viveiristas em seu contexto de trabalho, o que confere Educação Ambiental e ampliação de conhecimentos também em espaços não-formais de ensino. 
A oficina, locus deste estudo, contribuiu para difundir conhecimento ecológico e florístico na região de influência do Projeto de Integração do São Francisco. Junto a isso proporcionou diálogo sobre a temática com agentes locais para amparar ações emancipatórias de sensibilização e Educação Ambiental no contexto local de atuação da Rede de Sementes do PISF.

Por fim, este estudo auxilia no planejamento de atividades de sensibilização e Educação Ambiental visando a capacitação profissional realizadas pela Rede de Sementes do PISF e outras iniciativas semelhantes. Baseado nos resultados encontrados é possível planejar estrategicamente ações que acrescentem ao conhecimento sobre o ecossistema onde os sujeitos trabalham, estudam e interagem constantemente. Contribuindo de maneira direta ou indireta para a recuperação e conservação da Caatinga.

\section{Agradecimentos:}

Os autores agradecem ao Núcleo de Ecologia e Monitoramento Ambiental - NEMA, a Universidade Federal do Vale do São Francisco - UNIVASF, ao Projeto de Integração do Rio São Francisco com as Bacias Hidrográficas do Nordeste Setentrional - PISF e ao Ministério do Desenvolvimento Regional - MDR pela doação das sementes, apoio institucional e logístico para realização desta pesquisa. Ao professor Évio Galindo pelo empenho em promover a oficina para os estudantes do Instituto Federal do Sertão Pernambucano, a equipe do viveiro de mudas municipal de Bodocó-PE e do viveiro da comunidade indígena Bem-querer de Cima em Jatobá-PE pela participação na oficina..

\section{Referências}

ALBUQUERQUE, U.P. et al. How ethnobotany can aid biodiversity conservation: reflections on investigations in the semi-arid region of NE Brazil. Biodiversity and Conservation, v. 18, n. 1, 2009.

ALBUQUERQUE, U.P. et al. Medicinal plants of the caatinga (semi-arid) vegetation of NE Brazil: A quantitative approach. Jornal of Ethbopharmacology, v. 114, n. 3, 2007.

ALMEIDA, W.R. et al. The alien flora of Brazilian Caatinga: deliberate introductions expand the contingent of potential invaders. Biological Invasions, v. 17, n. 1, 2015.

ANDRADE, L.A; FABRICANTE, J.R.; OLIVEIRA, F.X. Impactos da invasão de Prosopis juliflora (sw.) DC. (Fabaceae) sobre o estrato arbustivo-arbóreo em áreas de Caatinga no Estado da Paraíba, Brasil. Acta Scientiarum. Biological Sciences, v. 32, n. 3, 2010.

ANDRADE, L.A.; FABRICANTE, J.R.; OLIVEIRA, F.X. Invasão biológica por Prosopis juliflora (Sw.) DC.: impactos sobre a diversidade e a estrutura do componente arbustivo-arbóreo da caatinga no Estado do Rio Grande do Norte, Brasil. Acta Botanica Brasilica, v. 23, n. 4, 2009. 
BARBOSA, J.A.A. et al. Caracterização da Caatinga segundo pais de alunos de uma escola privada no município de Campina Grande - PB. Revista de biologia e ciências da terra, v. 12, n. 1, 2012.

BARBOSA, J. A. A.; BARBOSA, R. K. V. C. "Visões de um semiárido": a diversidade biológica da Caatinga na óptica de alunos da rede pública de ensino no agreste paraibano. BioFar - Revista de Biologia e Farmácia, v. 6, n. 1, 2011.

BFG. Growing knowledge: an overview of seed plant diversity in Brazil. Rodriguesia, v. 66, n. 4, 2015.

BITENCOURT, R.B.; MARQUES, J.; MOURA, G.J.B. O imaginário sobre a Caatinga representada nos desenhos infantis de estudantes do Nordeste do Brasil. Revista Brasileira de Educação Ambiental, v. 9, n. 2, 2014.

BRANDALISE, L.T. et al. A percepção e o comportamento ambiental dos universitários em relação ao grau de Educação Ambiental. Gestão e Produção. v. 16, n. 2, 2009.

BRASILEIRO, R.S. Alternativas de desenvolvimento sustentável no semiárido nordestino: da degradação à conservação. Scientia Plena, v. 5, n. 5, 2009.

CRESWELL, J.W. Research Design: Qualitative, Quantitative, and Mixed Methods Approaches. 4. ed. Thousand Oaks: Sage Publications, 2014.

CRUZ, F.R.S.; ANDRADE, L.A.; FEITOSA, R.C. Produção de mudas de umbuzeiro (Spondias tuberosa Arruda Câmara) em diferentes substratos e tamanho de recipientes. Ciência Florestal, v. 26, n. 1, 2016.

CUNHA, A.O. et al. Efeitos de substratos e das dimensões dos recipientes na qualidade das mudas de Tabebuia impetiginosa (Mart. Ex D.C.) Standl. Revista Arvore, v. 29, n. 4, 2005.

DAVIS, M. et al. Don't judge species on their originS. Nature, v. 474, n. 7350 , 2011.

DIAS, G.M.; BONOTTO, D.M.B. As dimensões local e global nos entendimentos e práticas de professores participantes de um curso de formação continuada em Educação Ambiental. Revista Electrónica de Enseñanza de las Ciencias, v. 11, n. 1, 2012.

DRYFLOR. Plant diversity patterns in neotropical dry forests and their conservation implications. Science, v. 353, n. 6306, 2016.

DUQUE, J.G. O Nordeste e as lavouras xerófilas. $4 a$ ed. Fortaleza: Banco do Nordeste do Brasil, 2004.

FEINERER, I.; HORNIK, K. tm: Text Mining Package. R package version 0.77. 2019. Disponível em: <https://CRAN.R-project.org/package=tm>. Acesso em: 29 abr. 2020. 
FELLOWS, I. wordcloud: Word Clouds. R package version 2.6. 2018. Disponível em: <https://CRAN.R-project.org/package=wordcloud>. Acesso em: 29 abr. 2020.

FLORA DO BRASIL 2020 EM CONSTRUÇÃO. Jardim Botânico do Rio de Janeiro. Disponível em: <http://floradobrasil.jbri.gov.br/>. Acesso em: 06 jun. 2020.

KNOWLES, M.S.; III, E.F.H.; SWANSON, R.A. Aprendizagem de resultados: Uma abordagem prática para aumentar a efetividade da educação corporativa. Rio de Janeiro: Elsevier, 2009.

LEMOS, G.N.; MARANHÃ, R.R. O viveiro educador como espaço para Educação Ambiental. Ambientalmente Sustentable, v. 2, n. 6, 2008.

MANHÃES, A.P.; et al. Spatial associations of ecosystem services and biodiversity as a baseline for systematic conservation planning. Diversity and Distributions, v. 22, n. 9, 2016.

MILER, J.R. Biodiversity conservation and the extinction of experience. Trends in Ecology and Evolution, v. 20, n. 8, 2005.

NASCIMENTO, V.T. et al. Rural fences in agricultural landscapes and their conservation role in an area of caatinga (dryland vegetation) in Northeast Brazil. Environment, Development and Sustainability, v. 11, n. 5, 2009.

PALMA, A.C.; LAURANCE, S.G.W. A review of the use of direct seeding and seedling plantings in restoration: what do we know and where should we go? Applied Vegetation Science, v. 18, n. 4, 2015.

PAODJUENAS, R. et al. Conhecimento tradicional e usos do umbuzeiro (Spondias tuberosa Arruda) por comunidades rurais do semiárido, Paraíba, Nordeste, Brasil. Ethnoscientia, v. 4, n. 1, 2019.

PEREIRA, M.S. Manual técnico: Conhecendo e produzindo sementes e mudas da Caatinga. Fortaleza: Associação Caatinga, 2011.

PROENÇA, M.S.; DAL-FARRA, R.A.; OSLAJ, E.U. Espécies Nativas e Exóticas no Ensino de Ciências: uma Avaliação do Conhecimento dos Estudantes do Ensino Fundamental. Contexto \& Educação, v. 32, n. 103, 2017.

RODRIGUES, R.R. et al. Large-scale ecological restoration of high-diversity tropical forests in SE Brazil. Forest Ecology and Management, v. 261, n. 10, 2011.

SALA, A.; WOODRUFF, D.R.; MEINZER, F.C. Carbon dynamics in trees: Feast or famine? Tree Physiology, v. 32, n. 6, 2012.

SANTIAGO, L.S. et al. Drought survival strategies of tropical trees. In: GOLDSTEIN, G.; SANTIAGO, L.S. (eds). Tropical Tree Physiology. Springer. 2016. 
SILVA, A.C.; SOUZA, A.F. Aridity drives plant biogeographical sub regions in the Caatinga, the largest tropical dry forest and woodland block in South America. PLoS ONE, v. 13, n. 4, 2018.

SILVA, J. M. C.; LEAL, I.R.; TABARELLI, M. Caatinga: the largest tropical dry forest region in South America. Springer. 2017.

SILVA, V.A.; ANDRADE, L.H.C. O significado cultural das espécies botânicas entre indígenas de Pernambuco: o caso Xucuru. Biotemas, v. 17, n. 1, 2004.

SOUZA, K.R.; KERBAUY, M.T.M. A abordagem quanti-qualitativa: superação da dicotomia quantitativa-qualitativa na pesquisa em educação. Educação e Filosofia, v. 31, n. 61, 2017.

URZEDO, D.I. et al. Seed Networks for Upscaling Forest Landscape Restoration: Is It Possible to Expand Native Plant Sources in Brazil? Forests, v. 11, n. 3, 2020.

TUAN, Y. Topofilia: Um estudo da percepção, atitudes e valores do meio ambiente. 1 ed. Londrina: Eduel, 2012.

VOGGESSER, G. et al. Cultural impacts to tribes from climate change influences on forests. Climatic Change, v. 120, n. 3, 2013.

YIN, R.K. Estudo de caso: planejamento e métodos. 2 ed. Porto Alegre: Bookman, 2001. 